\title{
Designing with Users: A Participatory Design as a Community Engagement Program in the City Zoo
}

\author{
Yulia Nurliani Lukito \\ Department of Architecture, Faculty of Engineering, Universitas Indonesia, Depok, Indonesia, \\ yulia.lukito@gmail.com \\ Nevine R. Kusuma \\ Department of Architecture, Faculty of Engineering, Universitas Indonesia, Depok, Indonesia
}

See next page for additional authors

Follow this and additional works at: https://scholarhub.ui.ac.id/ajce

Part of the Environmental Design Commons, Landscape Architecture Commons, and the Urban, Community and Regional Planning Commons

\section{Recommended Citation}

Lukito, Yulia Nurliani; Kusuma, Nevine R.; Arvanda, Enira; and Ummah, Zafira R. (2021). Designing with Users: A Participatory Design as a Community Engagement Program in the City Zoo. ASEAN Journal of Community Engagement, 5(1), 49-70.

Available at: https://doi.org/10.7454/ajce.v5i1.1079

Creative Commons License

(c) (i) ()

This work is licensed under a Creative Commons Attribution-Share Alike 4.0 License.

This Research Article is brought to you for free and open access by the Universitas Indonesia at ASEAN Journal of Community Engagement. It has been accepted for inclusion in ASEAN Journal of Community Engagement. 


\title{
Designing With Users: A Participatory Design as a Community Engagement Program in City Zoos

\author{
Yulia Nurliani Lukito ${ }^{1 *}$, Nevine R. Kusuma ${ }^{1}$, Enira Arvanda ${ }^{1}$, Zafira R. \\ Ummah $^{1}$
}

${ }^{I}$ Department of Architecture, Faculty of Engineering, Universitas Indonesia, Depok, Indonesia

*Correspondence email: yulia.lukito@gmail.com

Received: March 24, 2020, Accepted: July 12, 2021

\begin{abstract}
This article discusses a participatory design project that aims at creating a collaborative design among architectural students, visitors, and zoo management in designing street furniture and selfie spots in city zoos. Participatory design is used in the design process to get the users' and designers' interpretation of the space, improve design outcomes, and increase the community awareness of their surroundings. As part of the Universitas Indonesia Community Engagement Program, the zoo design project fosters a collaborative design between the university and zoo community and supports the educational, conservational, and recreational goals of Ragunan Zoo in Jakarta. Designing street furniture and selfie spots can hopefully be parts of improving the quality of public space in the zoo. Students and lecturers who usually have limited opportunity to collaborate now have a chance to interact with visitors and the zoo management during the research and design stages while visitors actively collaborate in informing their needs and perception of the space. The zoo management also provides information on their goals and missions so that students can develop and convert the education, conservation, and recreation goals of the zoo into designs. In conclusion, the participatory design approach applied in the zoo design not only allows students to deal with real-life issues in design but also enhances space quality through community participation.
\end{abstract}

Keywords: participatory design; community engagement; city zoo; public space; Ragunan Zoo; street furniture; selfie spot.

\section{Introduction}

Community engagement and participatory design has a strong connection. Some people even challenge how architects deal with local contexts and environmental issues in designing built environments because there is still a relatively limited collaboration between designers and users (Frampton, 1991; Sanoff, 2000). Recently, some designers and planners promoted community engagement in designing public spaces. Community engagement has recently gained popularity as a basis for good urban design, and it also has become a constant theme in design education. Participatory design is an approach that pushes all stakeholders, such as 
professionals, partners, and users, to actively collaborate in the design process to ensure that the result meets the needs of all stakeholders (Robertson \& Simonsen, 2012). The idea of participatory design, which emerged in the late twentieth century, views planning and design as an extending interrelationship among stakeholders, with dialogues as the crucial media to resolve a disagreement and engage in participatory actions (Holgersen \& Haarstad, 2009).

As an illustration, regular architecture programs usually focus on studio-based modules, where theories and practices are implemented in supposedly active learning formats (Rodriguez, 2017). The importance of active learning in architectural education has led to some experiments and strategies, including the use of participatory design methods (Pedersen, 2016; Sanoff, 2008) mentioned that users' participation during the design process in architecture is necessary. Community involvement is a part of non-inclusive design practices (Sanders \& Stappers, 2008). One of the approaches for introducing the participation concept is to offer students the opportunity to directly interact with users and expose them to social and cultural diversities (Hasanin, 2013; Salama, 2009). Learning from real-life experience can lead students to have lifelong habits of understanding public interest and building the skills needed to deal with the intricacies of real-life problems (Eyler, 2000; Sanoff, 2000).

Universitas Indonesia (UI) launched a community engagement program that aims to promote collaborations between the university and local communities, as a part of UI's responsibility to make real contributions to the society. This program allows the mutually beneficial exchange of knowledge and resources, in a context of partnership and reciprocity, between institutions of higher education and communities. Researchers have documented university-community partnerships that have reinforced faculty, students, institutions, and communities. They have found that, among other advantages, learning from real-life experiences can allow students to have lifelong habits of understanding public interest and building skills needed to deal with the intricacies of real-life problems (Eyler, 2000; Sanoff, 2000). The project discussed in this paper is a collaboration between the design team from the Department of Architecture of UI and the management of Ragunan Zoo in developing public space design in the zoo.

There has been a rise in interest on public participation in the development of public spaces derived from the recognition of people's potentials to contribute to design decisions related to local beliefs and attitudes (Arnstein, 1969; Moomaw, 2016). Participatory design means investigating, understanding, and supporting reciprocal learning processes through bottom-up design methods as they unfold among participants during the design process. It inevitably requires the participation of users and stakeholders in the design process (Kensing \& 
Greenbaum, 2012), including the designer who should provide ways for a user to share their own ideas and insights. A designer should have insights into how to facilitate a collective design process within academic and practical approaches to have the best of creativity and to take users as design partners (Sanders \& Stappers, 2008). This approach is applicable for designers who aim to learn the realities of the situation of those who will use their designs, and the participatory design process can improve the quality of public space design and community awareness of their surroundings (Booher, 2008; Howarth et al., 2017). It is important to understand how the design process should be organized and who should be involved on the design work to obtain a good understanding.

This article aims to discuss the participatory design process and how the process that provides real situations in design help to enhance the quality of a public space. The participatory design methods offer users to understand the design process and reveal an unexpected depth of the problem that a simple quantitative approach usually cannot show (Guijt, 2014). We collaborated with our partners in Ragunan Zoo, so that students can participate in designing public spaces in the zoo. A participatory design allows design students to have an opportunity to conduct research and propose a public space design in the zoo that suits the existing conditions, needs of visitors, and zoo management. Accordingly, this effort may enhance the quality of visits through educative and fun experiences for visitors (Clayton, Fraser, \& Saunders, 2009). Design intervention can help visitors to value their visits, learn from zoo collections, and participate in the conservation. The project is expected to improve the ability of visitors to enjoy their visits and have time to learn from the surroundings because zoos have a significant role in the conservation and education program (Correa de Jesus, 1994; Cornell, Sorenson, \& Mio, 2003). The goal is to create a memorable visit for visitors while in the zoo and to learn from the surroundings.

Ragunan Zoo, located in the south of Jakarta, is home to 2,000 specimens and more than 50.000 trees. It has become a popular holiday destination for people who live in Jakarta and its surrounding areas. The 14-hectare zoo offers an affordable entrance price for people to enjoy animal collections and a large greenery area. The zoo is also one of the favorite destinations of families and school children to have good recreation and educational spaces. It gives a comfortable environment and public space for the people in the city. Aside from educational and conservational facilities, such as Schmutzer Primate Centre and animal collections, the zoo also provides recreation centers for visitors to spend their holidays. However, the existing zoo facilities, such as outdoor furniture, are not sufficient for visitors, and some even have an unsatisfactory design. 
There are some design issues that the zoo management has to deal with so that they can serve their visitors better, take care of animal collections, and educate visitors on animals and the environment. For instance, there is limited animal information and a lack of signage that confuse visitors in exploring the zoo. The lack of animal information and public facilities reduces visitors' motivation to fulfill education and conservation purposes visitor satisfaction with zoo experience is related not only to safety and sustainability but also to information services and recreation facilities (Coley, 2019). In addition, urban zoos have potential to provide a healthy public space for the city, which is not yet thoroughly elaborated in most urban zoos (Jabareen, 2006).

The concept of providing street furniture and selfie spots in zoos aims to enhance the quality of visits, support social interaction among individuals, and make the surrounding environment a more pleasant place for interaction. Therefore, the zoo management's need for a good street furniture design integrated with circulation, public space, and attractions in the zoo is very significant. The concept of designing a selfie spot is also proposed by the zoo management to create memorable visits for visitors.

This paper discusses the participatory design process in designing street furniture and selfie spots in Ragunan Zoo and argues that using participatory design knowledge in creating street furniture and selfie spots can promote strong collaboration among zoo management, design professionals, design students, and visitors. Offering the opportunity to directly work together with real clients and users for design students is arguably the best strategy for introducing participatory design (Salama, 2009). In addition, good integration among stakeholders in the zoo by providing integrated street furniture and selfie spots to the existing zoo contexts helps to create landmarks and unique identities of public spaces in the zoo.

\section{Methods}

In this study, participatory design projects, results, and significance of collaboration for stakeholders, including architectural students, were analyzed. Quantitative and qualitative approaches were used in analyzing the design process and assessing the results of the projects. The quantitative method was used in mapping and documenting existing conditions, such as vegetation, landscape, and traffic patterns. As a way to map existing conditions, the team conducted site visits at various times, such as during weekdays and weekends and in the morning and afternoon and observed the use of space and visitor activities. Between March and May 2019, the teams conducted a site visit and interviewed visitors to determine activity patterns. After analyzing the activity patterns and existing physical conditions of the site, the 
teams elaborated on the possible interaction of visitors in the zoo and proposed some design ideas.

This project aims at a collaboration project in which the management, design students, lecturers, and visitors were included in the process and benefited from the design project. According to a community-based perspective, the participation of community members should be central to create local concerns (Moomaw, 2016). In this Ragunan Zoo design project, the mapping of visitors' movements and preferences while in the zoo is significant for the decision taken during the initial design.

The study uses a qualitative method, such as acquiring information on how visitors have their preferences in exploring the zoo. The team conducted site visits and analyzed existing conditions, interviews, and discussions, especially in understanding responses from users and feedbacks for the design project. Through visitor participation, such as determining which collections and paths in the zoo are crucial for their visit, the proposed design arguably helps to improve the quality of public space and make the surrounding environment a more pleasant place for interaction (Roe, McConney, \& Mansfield, 2014).

The significance of this participatory design relates this project to the idea of community engagement, in a way that zoo management not the only party concerns who should decide how visitors explore the zoo. Participatory design means strengthening reciprocal learning processes through a bottom-up design approach as they open up the needs of participants during the design process. The participation of community members should be essential for copying user concerns and local contexts (Cleaver, 1999). This approach is very relevant for designer students who want to learn the realities of situations.

The participatory design process for street furniture and selfie spots for Ragunan Zoo goes through several stages: First, the team undergoes preparation during the lecture time, which includes a literature study to determine relevant references for the design. The team discussed the results of the literature study and made a focus group that comprises architectural students, zoo management, and experts in landscape and furniture designing to obtain inputs for the design concept.

Second, a field survey was conducted to map the vegetation, contour, sunlight, and possibility of development. The survey involved observing visitors' behaviors and understanding how to integrate the elements of furniture used for various purposes, such as seating, pointing directions, and selfie spots, which simultaneously can create a new impression of the place. Analyzing user behaviors provides valuable information on traffic patterns, and survey studies reveal characteristics needed in accommodating user preferences. The data 
gathered were then analyzed so that students could create a response to the need for street furniture and selfie spots and a comprehensive design and give a memorable experience for visitors. The team created initial designs, conducted discussion sessions, and then presented the results to the zoo management.

Third, in the design stage, the students proposed design alternatives to enhance visitors' experience in exploring the zoo. These proposals were presented to the zoo management to obtain some feedback for the development. The design stage is a crucial stage of the process as suggestions and opinions from visitors and the zoo management are valuable in making decisions and developing the design. We believe that visitors can give valuable inputs for the program in designing public spaces or themes that emerge from the mapping of how visitors explore the zoo. This stage is an effort to connect designers and users and offering a possibility to improve the quality of public spaces in the zoo.

\section{Results and discussion}

Public spaces in the zoo have undergone changes with the changes of the city, such as the spread of the modernist vision and ideas of conservation and diversity. Nowadays, a zoo is not only a collection of animals that offers leisure and entertainment. It has also become a potential public space for increasing community interactions. Some ideas and efforts have been used to promote public engagement with the development of public spaces, including public spaces in the zoo. Accordingly, good strategies are required to have good partnerships between designers and users. Universities, with their resources and networking, can contribute to the development of urban areas and capacity by applying some design theories and methods to local contexts (Benneworth, Charles, \& Madanipour, 2010).

Street furniture is an essential part of the urban outdoor design; the collection of furniture placed on streets serves different purposes and significantly contributes to the urban experience (Uffelen, 2010). Street furniture covers various items, such as lamp posts, benches, and signages. Street furniture provides various purposes in public spaces, such as comfort, seating, lighting, necessary information, and protection. Designers should integrate street furniture into public spaces to strengthen the interaction among individuals. Regardless of the type of furniture set into the public space, the functional and physical properties should be carefully designed to support users' needs and enhance the surroundings. The role of street furniture serves similar purposes with the furniture in a house that renders urban spaces livable. Street furniture, in this case, constitutes a significant role in activating urban identity (Uffelen, 2010). 
Selfies are photos that one has taken of oneself, usually using smartphones. They become a form of communication through the image that people create to express themselves to their surroundings. They also work as a visual memory of events and experiences that individuals have. In this regard, it is merely natural for people to take some pictures during their visits to recreational places or tourist destinations. Concerning Ragunan Zoo, there are limited spots designated for selfie spots and supporting features to create a visual memory experience. Accordingly, to reinforce the meaning of a place, a designer should use the physical form as a point of reference (Lynch, 1960). Creating street furniture and selfie spots in Ragunan Zoo can be related to building landmarks and specific identities for particular attractions and important places. Therefore, designers should integrate street furniture and selfie spots into existing conditions and the attractions in the zoo. In a broader perspective, creating landmarks and identities for spaces can be a part of a branding strategy for zoo management as providing pleasant places for interaction.

During the last three years, we have administered various community engagement programs with Ragunan Zoo in Jakarta, which mostly used a participatory design approach to support zoo management in designing public facilities in the zoo. The topics for the design project come from the proposed plan of the zoo management to the government in early January. We usually submit a proposal to UI to get some funding for the operational cost. In our community engagement program, creative ideas were derived from the good collaboration with zoo management and visitors, so it is necessary to have a good engagement with the local community. The purpose of this design project is to design street furniture that supports visitors' needs in exploring the zoo. By providing facilities in the public space, visitors can hopefully have a good time and a memorable visit. One of the important things is finding out the uniqueness of existing features and how people use the space.

The collaboration in the projects includes various actors, such as a group of architectural students and three lecturers who want to conduct research and propose a design in the zoo environment. Forty students from the "Furniture: Context, Response, and Object" class joined the project during the semester event in 2019. Other important actors are visitors who actively provide information and set the needs and the zoo management, which includes the Information and Service Department and Facilities Department, who will eventually implement the designs. There are two crucial points in the zoo design. The first is creating a unique experience for the visitors and the second is connecting visitors to the idea that a zoo is a place for education (Coe, 1985; 1997). The second point may be visualized from the idea of a naturalistic zoo environment that gives visitors the sense of being in the habitats of animals. 
Architects play a significant role in engaging the public into the design process and have capability over the methods and tools in designing. However, the results may involve technical and complex processes that are often different from the daily expressions that people may have in their lived experiences (Holgersen \& Haarstad, 2009). Moreover, the interrelation issue between professionals possibly restricts the participation of some people. The involvement of design students can help in bridging professionals and users while also offering an understanding of how participatory design can create satisfactory expression for users. Students can facilitate the two ends through their access to professionals' consultations and their affiliation with universities and fascination to learn from their surroundings. Based on the participation design, students may have a role to make design a more tactical practice, and lecturers have a role to expand thinking from an educational perspective and promote mutual understanding between designers and users.

The design process involved several stages: First, the team, which consisted of lecturers and architectural students, conducted a literature study to have some references on zoo and street furniture designs. Then, the team conducted field surveys to map existing features-natural and built environments-and generate some possibilities in the design. In this stage, the team interviewed visitors and observed their pattern in exploring the zoo, including how visitors wanted to experience the space. All of this information was then analyzed and discussed with the zoo management to obtain feedback for the development of the design. Later on, the team proposed some design alternatives for the street furniture and selfie spots concerning existing conditions in Ragunan Zoo. During this stage, the team also organized a focus group discussion involving the management, design professional, and architectural students.

During the early stage conducted in the studio, students were divided into small groups, and each group surveyed the need for street furniture and selfie spots in Ragunan Zoo. The observation performed at the survey included documentation of site properties, attractions, visitor behaviors, and interviews with visitors and the zoo management. During the survey, the students tried to understand the site and interacted with visitors so that they could propose ideas that came from a combination of the site analysis and the response of zoo visitors. Students developed their design ideas with an active discussion among group members and lecturers and then presented them to the zoo management. 


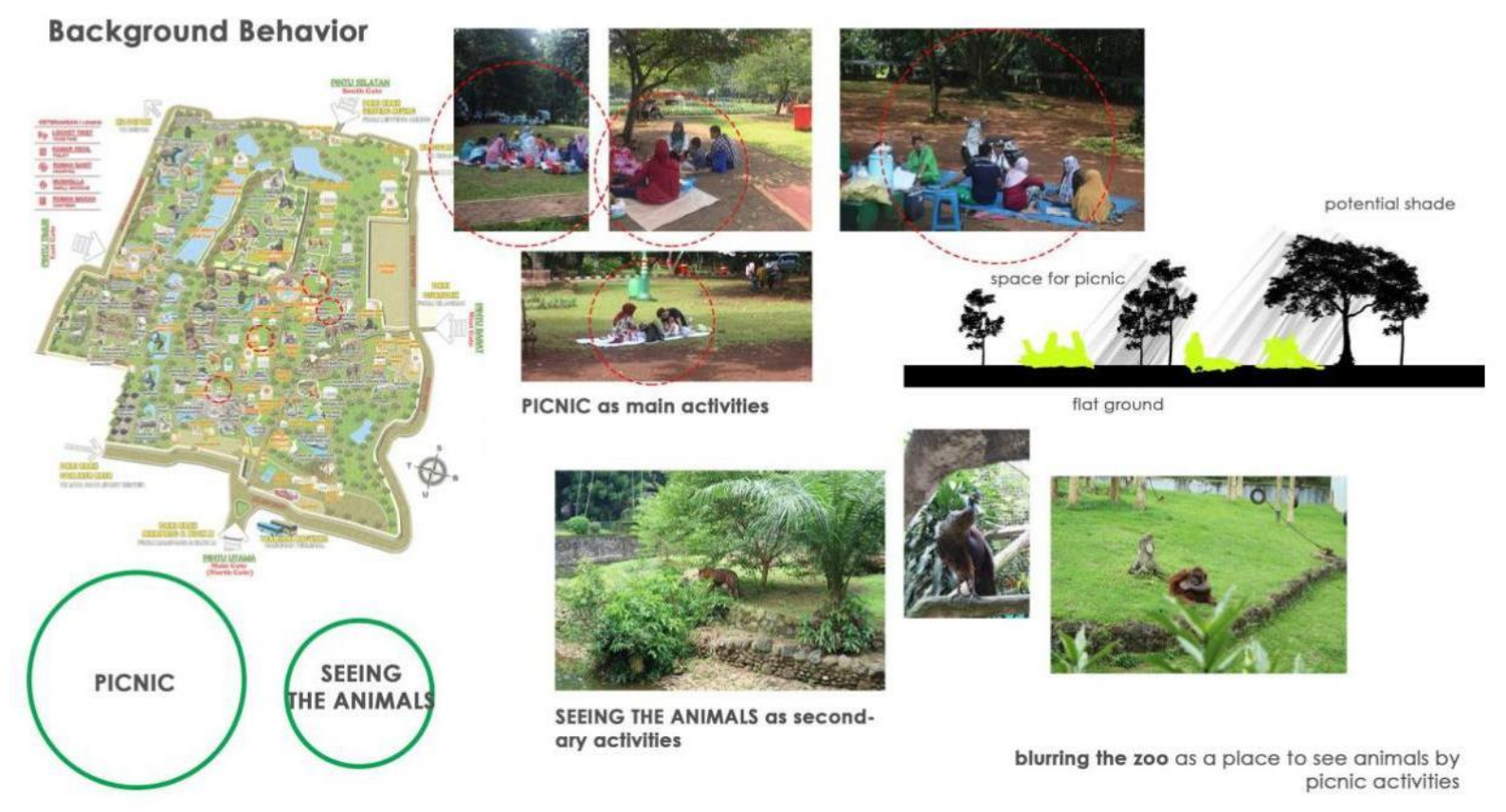

Figure 1. Study of visitor behaviors in the zoo

Source: Department of Architecture, Faculty of Engineering, Universitas Indonesia (2019)

It is necessary to create a unique experience for visitors and connect the experience with the bigger idea of having the zoo as a place for community education and immersing the zoo habitat (Coe, 1997; Hone, 2014; Ludlum, 2003). Therefore, the team comprehensively analyzed the site to determine potential sites that are crucial for the street furniture design. As seen in Figure 1, students identified important points, especially from their site surveys, for their initial design program. These points included providing facilities for visitors by accommodating existing vegetation, light intensity, visitor flow, and specific activities related to attractions in certain places. The results were several design options made by considering the existing vegetation, visitors' experience, and budget. 

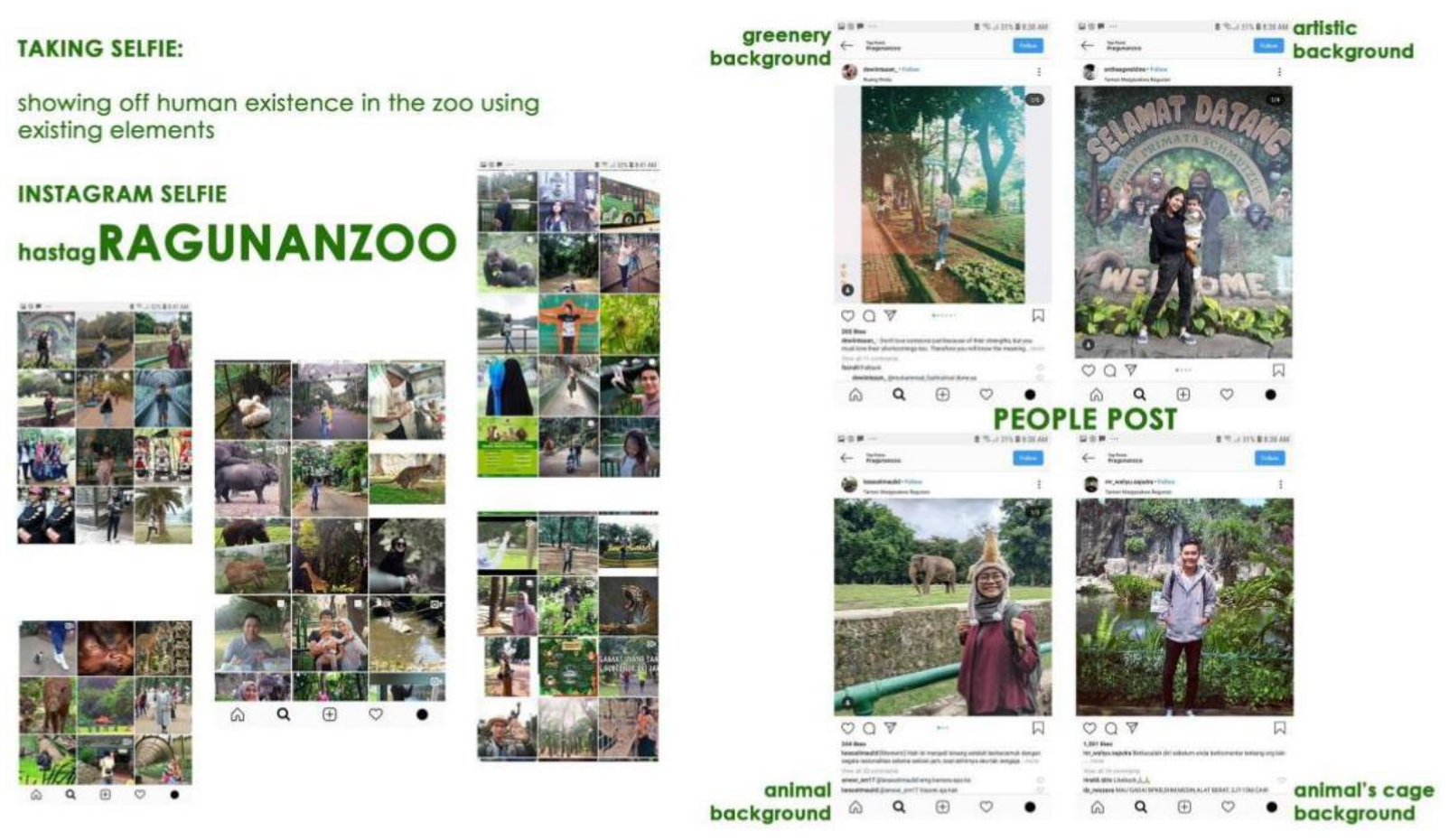

Figure 2. Analysis on how visitors take selfies

Source: Department of Architecture, Faculty of Engineering, Universitas Indonesia (2019)

The site studies conducted by the students resulted in the understanding of visitors' behavior and pattern in using spaces in the zoo. For example, places with good backgrounds, complexity of sunlight and shading, and having sufficient properties seemed to invite visitors to take a selfie. As Whyte (1980) said, “... the quality of experience, which can be much greater when there is sun." Based on this statement, people tend to seek the sun, and given the right spots, they will sit in surprising numbers under the shade. Moreover, preferred and settled furniture can attract people to outdoor spaces and enjoy using these spaces (Yücel, 2013). The findings were essential for designing selfie spots. The selfie spot design should be attractive. Accordingly, it can become a passive-active branding and promotion tool for the zoo through the visitors' social media. Figure 2 depicts examples of attractive backgrounds that include greenery, animals, or cages and some public arts, such as murals, that give aesthetic quality and identity to the place.

In designing the street furniture and selfie spots, students also conducted programming and implementation. In the programming stage, possible furniture was plotted on a map. During this stage, the students proposed a strategy to design the furniture and selfie spots as a way to connect the designated spaces with entrances and important decision points to reach favorite destinations. The appropriate integration of street furniture into the design of a public space 
constructs identity and evolves a sense of place around it. Therefore, each group of students needed to propose the concept of selfie spots as the integration of visitor behavior and buildability. As expected, each group came up with various design alternatives and scenarios in the zoo considering that they had observed and interviewed different target groups. Design ideas were then presented to the zoo management, which were deemed unique and creative because they were derived from various interpretations of the site and users' behaviors.

The following part is a discussion of the process and results of student involvement in the participatory design process.

One of the groups designed a selfie spot that served as a complex landmark and signage to help visitors in exploring more areas of the zoo (see Figure 3). These selfie spots become public works of art that can serve as focal points on streets and in public areas, and eventually, they can give these spaces a unique character. The group considered animal attraction with how people wanted to enjoy the space while resting and sitting. The idea of the design was derived from visitors' favorite paths in exploring the zoo and the sequence of attractions that visitors would encounter. A designer should consider users' needs and preferences in designing a successful installation in a public space. The students analyzed the kind of expectation that visitors had while approaching animal cages and overlapped their analysis with the characteristic of animals in the chosen place to create a layering concept. The idea was to have "pose spots"-each spot was in a form of a favorite animal located near the cages. The layering parts of the animals created unique sculptures. With a comprehensive understanding of visitors' behaviors and good design, the results of the design allowed some possibilities for users to take pictures. The design process resulted in pieces of enthralling street furniture that not only are usable and attractive but also give artistic enrichment for visitors. 


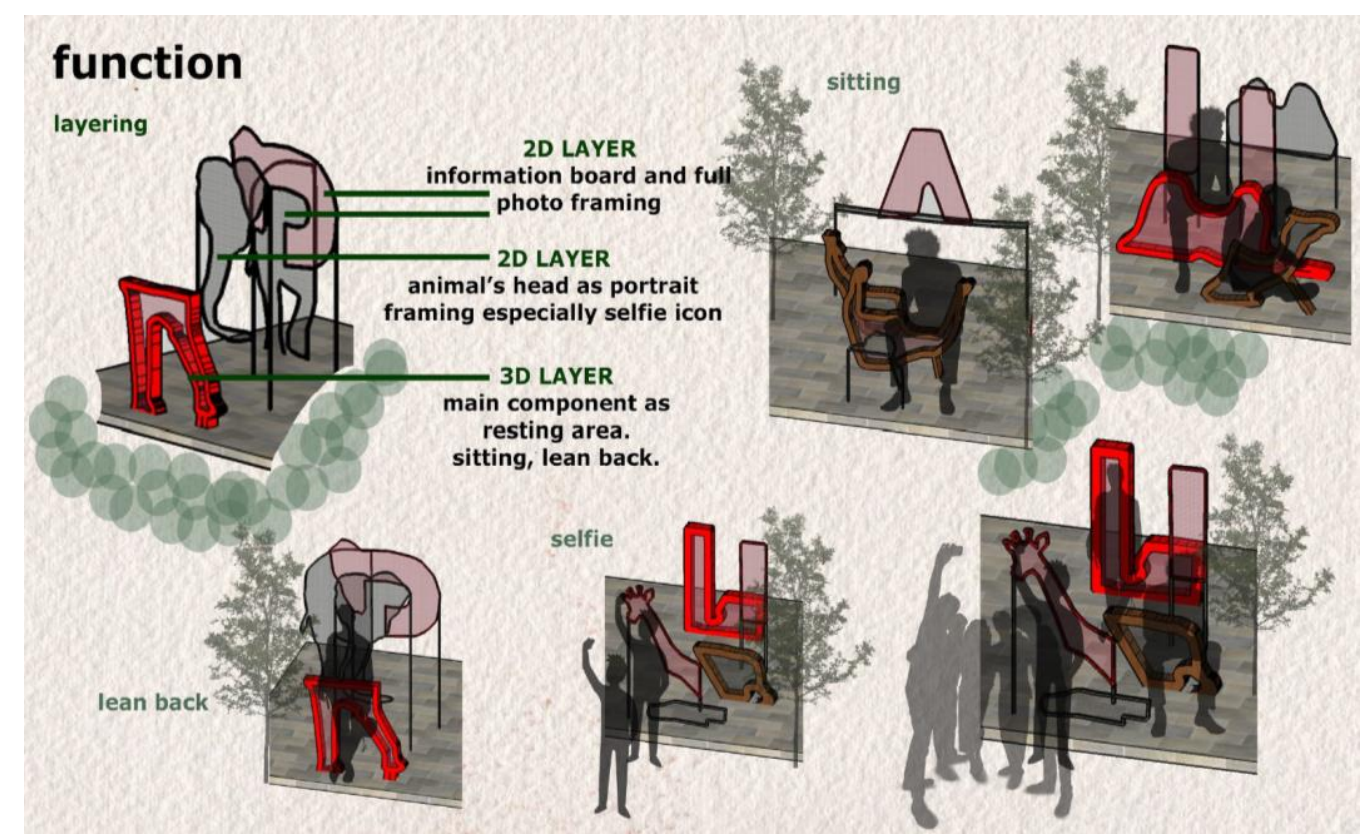

Figure 3. Design of "Ragunan Word Hunt" proposed by the students

Source: Department of Architecture, Faculty of Engineering, Universitas Indonesia (2019)

Another group put their focus on giving information on animals and their habitats as part of their proposal. This group created a "game" to match figures of animals with information on their habitats embedded in a series of boxes put in areas suitable for selfie spots. When visitors play the game, they focus on the display contents, which in turn raises visitors' engagement with the educational messages (Budge, 2018). Although some groups seemed to deal with only one small area, the process of deciding which area they would take as their spot included an understanding of how visitors will be intrigued by the boxes and use them as a fun game. The results showed an exploration of information that should be placed on the box surfaces and the ability to integrate colors, materials, and layouts of information for the boxes. 


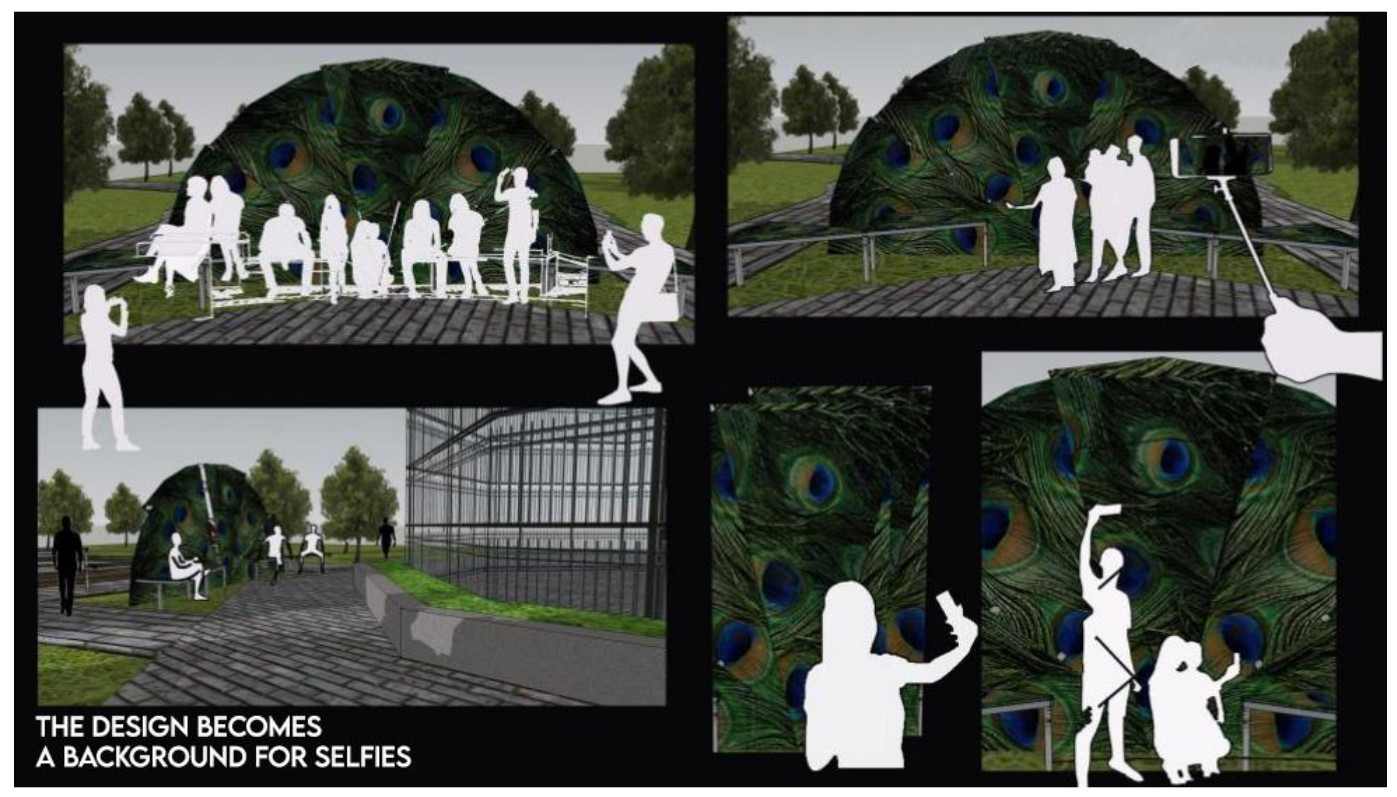

Figure 4. Design of the "peacock" selfie spot proposed by the students

Source: Department of Architecture, Faculty of Engineering, Universitas Indonesia (2019)

Figure 4 shows another example of the selfie spot design made by the students. The selfie spot is located in front of a peacock cage. In the design process, the students integrated knowledge of site properties, such as the cage, with the visitors' behaviors. The students considered the location of animal cages and how visitors approached them before they decided where to put the selfie spot. Furthermore, public art enriches the environment and brings public spaces to life, ranging from objects to an entire streetscape (Cartiere \& Willis, 2008). The design was intended to be iconic and could be seen from various pathways so that visitors could create a visual connection with many areas in the zoo. Aside from its function as a landmark, the selfie spot also functioned as a furniture for the visitors to rest and watch peacocks.
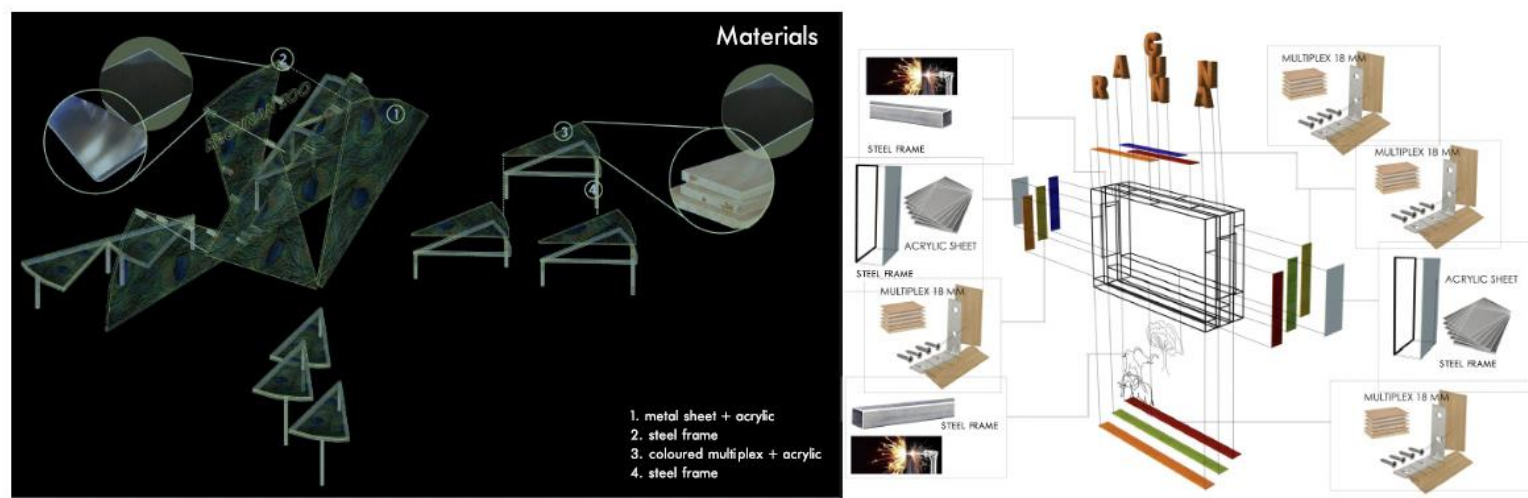

Figure 5. Proposed materials for the selfie spots designed by the students

Source: Department of Architecture, Faculty of Engineering, Universitas Indonesia (2019) 
All of the groups needed to propose suitable materials for the furniture, and they had to consider cost, portability, durability, utility, and aesthetic choice. Students went as far as calculating the production cost of their design with the selected materials to have the budget approval by the zoo management (see Figure 5). As shown in Figure 6, the students created mockups in the studio to assess their design idea and tested its buildability. Finally, design professionals evaluated the practicality of the implementation.
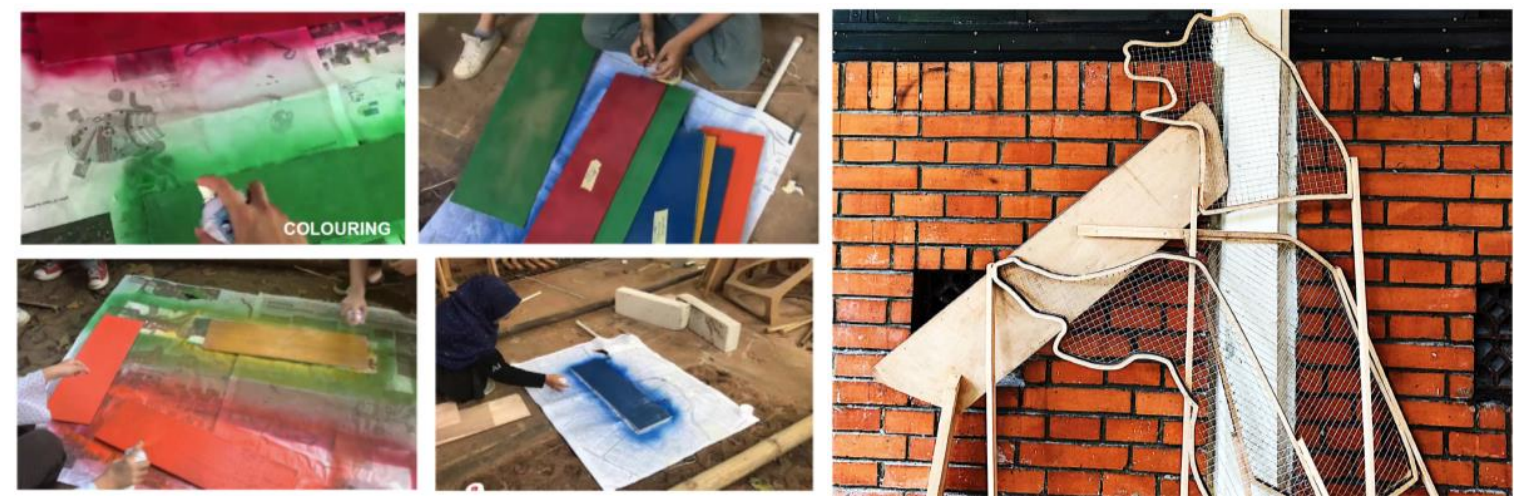

Figure 6. Mockups of the selfie spots made by the students

Source: Department of Architecture, Faculty of Engineering, Universitas Indonesia (2019)

The street furniture and selfie spot project allowed students to be involved in the design process. The students actively attempted to figure out the best way to deal with conditions on the site. Participatory design requires students to have hypothetical thoughts to help them proceed through the existing conditions and problem-solving processes. This approach stimulates learning outside the studio for students and makes them think and assess their decisions throughout the design process. The role of lecturers in this project is to supply and facilitate students with the necessary tools and resources to solve the problem. The participatory design allows lecturers and students to engage in a student-centered pedagogical method of designing while also giving real-life experiences for students to learn and contribute to the society.

The involvement of zoo communities shows a process of non-inclusive design practices (Sanders \& Stappers, 2008) that connect designers with users from the early design stage. The design process enables designers and users to perceive, understand, and interact. In the case of Ragunan Zoo's participatory design, although the usability for people has something to do with general use, participatory is the key for public space design with large audiences like that in a zoo. Feedback from these audiences is not easy to receive, and the feedback can be effective for a wider range of people who visit the zoo. Moreover, the participatory design project in 
Ragunan Zoo does not aim to create a single solution for most visitors but to supplement a design idea to accommodate visitors' activities in specific spaces in the zoo.

Introducing the concept of participation to architectural students means offering students the opportunity to interact with users (Hasanin, 2013; Salama, 1995). The interaction also allows students to determine various responses to the site based on different times and uniqueness of places and social and cultural diversities. Finding out visitors' expectations while approaching animal cages can be performed through a comprehensive study of how people want to interact with the space and animals and how they act in groups. During the design phase, all of the students agreed that user participation has extended their perspective on the design process.

Zoos have an important role in the conservation and education program (Cornell, Sorenson, \& Mio, 2003). The aim of designing the zoo is to create a good space for visitors to enjoy the collections and learn about animals, their habitats, and the conservation of the environment. Some modern zoos have elaborated a unique approach of translating the recreational needs of their visitors into a memorable experience for visitors and submitting them to a discrete set of conservation messages. Apart from the functionality, the public space design in the zoo is usually related to the zoo's educational role. The design is also related to how the design will contribute to the information and aesthetic needs of the visitors.

Participatory design means to support reciprocal learning processes through bottom-up design methods, and this approach is appropriate for design students who want to learn from real-life situations. Zoo environments provide information not only about animals and their habitats but also several attributes, such as social contexts. Social experiences allow acknowledging shared values for the environment and public space and using this knowledge for design. Therefore, the participatory design process can enrich the quality of public space and community awareness of their surroundings.

As a part of the participatory design, the students are encouraged to work together with users. The participatory design also includes an application of human behavior knowledge; for instance, zoo visitors are environmentally inclined to learn from and enjoy what they experience. The results of visitor behavior mapping will assist designers in designing and the zoo management in improving visitor experience. The fundamental goal is to encourage visitors' awareness and appreciation of animals and their habitats.

Along with the education function, zoo environments also have an entertainment function. By creating an emotionally engaging experience in zoos, such as taking selfies, the personal experience involving curiosity, fun, and connection to the environment can be impressive. Such 
connections can consequently provide an influential basis for empathy and concern animals and ecosystems. Through visitor participation, such as deciding the kind of collections and places in the zoo that are crucial for their visits, the proposed design arguably makes the surrounding environment a pleasant place for interaction. Thus, this design project may increase the quality of visits through educative and fun experiences (Clayton, Fraser, \& Saunders, 2009).

The quality of visits through experience means giving a memorable experience or an experience that will undoubtedly impress people in the long run. The way the students tried to create a situation that goes beyond the average stimulation is one way to achieve this. Creating a game, for instance, is a novel and emotional experience that reinforces memory and gives good entertainment and education. Creating an emotional connection among visitors, animals, and sites comes from the idea of experiencing the zoo. Designers have an opportunity to create an in-depth experience through a direct experience, surrounded by nature and immersion of place and living creatures. For instance, with the "Ragunan Word Hunt" design, visitors can feel personally involved and get excited about animal and nature conservation.

There are numerous opportunities for the use of the zoo in university programs. There is a need for close collaboration with university lecturers to elaborate on the potentiality of the zoo for enhancing learning and real-life experiences. Moreover, the zoo offers many possibilities for quality research, including environmental education and participatory design. The role of zoos to develop education is now accepted (Andersen, 2007; Eaza, 2008), and the broad spectrum of educational activities provided by zoos not only is related to animals and biodiversity but may also have cross-academic origins, such as design, technology, and health.

As a reflection of the design project with Ragunan Zoo, students gave their opinions of the whole process. They mentioned some benefits of the project. Having real clients means that they need to consider users' parameters, by which users can judge their works. In addition to contributing to the society, this kind of learning can be very informative for the design process. However, some students also mentioned that realizing a design from scratch to a product requires a lot of energy and collaboration, which sometimes makes them consider a personal approach to people. In short, the project added realism to the whole design process. Participatory design and real clients are relevant tools for enhancing relational and holistic thinking in design education. They initiated discussions, such as the use of local resources and the expression people used to convey their needs and lived experiences. Students were the neutral party who wished to learn actively from their surroundings. They could help bridge professionals and communities in the process of designing a public space. 
In using the zoo as a learning space, unpredicted learning happened that would not unlikely occur in a studio or a classroom. For example, the students could directly experiment with colors, shadows, or materials and projected their ideas in the zoo environment. Students learned these skills and knowledge through experience without being exposed to classroom or studiobased teachings. An interesting result was revealed during the process when some students had difficulty thinking about the outcomes of each design stage. For instance, visitor feedback on how they would use furniture and selfie spots placed in front of the animal cage was significant for the design stage.

The team evaluated the Ragunan Zoo participatory design from different perspectives. The students assessed their difficulties in each phase of the design program. In the early stage, the students had a bit of confusion to understand the participatory design process. However, they were interested in this alternative design method. From a designer's point of view, participatory design has become a tool for capturing diversity in designing public spaces. During the design stage, most of the participants agreed that visitors' participation develops their perspective on the design process. However, some students had difficulty deciding the variety of designs and the information to share with visitors. During the design development stage, the students realized that they need to have the ability to interpret the feedback from their design partners and connect it to the design solution.

The lecturers involved in the program also performed evaluation on the design process, which includes assessing the strengths and weaknesses of the participatory design. All lecturers agreed that participatory design is a good method in incorporating existing conditions with social interaction in design. There may be difficulties in the process if the designer's role and the way for facilitating the visitor's needs are not well defined. The zoo management also gives feedback for the program. For them, the participatory design requires systematic planning and more energy. However, the result is worth because participatory design creates a significant impact on the outcomes. Moreover, the zoo mangaement likes the active participation of the zoo community and the design creativity of the students.

The research and design process of street furniture and selfie spots shows good collaboration among stakeholders in the zoo and potential in implementing the participatory design. The students appreciate the opportunity to work with real clients and design contexts, and a collaboration exists among design students, lecturers, design professionals, zoo management, and visitors. Although the students knew from the very beginning that not all their designs will be built, they felt delighted to know that their ideas will become future references for zoo 
development. In the end, the Ragunan Zoo participatory design creates an opportunity for students to learn from real-life issues and enhance the quality of space in the Ragunan Zoo.

\section{Conclusion}

The Ragunan Zoo design project uses a participatory design approach that attempts to respond to the practical needs of the zoo and provide public space and facilities for its visitors. The project intends to create collaborative interactions among zoo management, visitors, and architectural students in design processes that improve the space quality in the zoo. The collaboration of designers from UI in designing street furniture and selfie spots in Ragunan Zoo serves various benefits for the stakeholders. The zoo management provides some insights into the process of enhancing the experience of visitors through the design. Designers and students can join the design process, which includes real design contexts and users to improve public space designs.

The project was conducted by examining visitors' behaviors and how to accommodate the elements of furniture used for different purposes, such as seating, giving information, and providing a selfie spot. To do so, the creative ideas of designers to form a good design can be obtained through the study of the needs and uniqueness of the location and analysis of how people use spaces in the zoo. During the process, students need to observe and interact with visitors in formal and informal ways while visitors play their role as partners in the discussion who can express their needs in the zoo.

This article aims to discuss how a participatory design provides students with an opportunity to learn from living experiences, conducting behavioral-based research, and recommending design solutions that students felt most connected to. This design collaboration can be applied to enhance a conventional studio-based module into a participatory and user-centered design. Visitors can participate by giving their opinions on the condition of the zoo and how to make it better. The zoo management generated their ideas and criteria of how the design should help the zoo to get their conservation, education, and recreation goals. Moreover, the participatory design process can improve the quality of the public space design and community awareness of their surroundings.

\section{Funding}

The implementation of the community program was funded by Universitas Indonesia through grant from the Directorate of Research and Community Engagement, Universitas Indonesia (Grant Number: NKB-1412/UN2.R3.1/HKP.05.00/2019). 


\section{Declaration of Conflicting Interest}

There is no conflicting of interest for this manuscript.

\section{Author Contribution}

Yulia Nurliani Lukito conceived the presented idea, developed the theory, led the project, and mostly wrote the article. Nevine Rafa Kusuma and Enira Arvanda led the design process with students. Zafira helped to write the early version of the manuscript. All authors discussed the results and contributed to the final manuscript.

\section{Short Biography}

Yulia Nurliani Lukito is a lecturer at the Department of Architecture Universitas Indonesia. She earned her bachelor's degree the Department of Architecture, Universitas Indonesia. Master's in design studies from Graduate School of Design, Harvard University, USA. She received her doctorate degree in Theory of Architecture from RWTH Aachen University, Germany. Her research interests are history and theory of architecture, modernity and colonial architecture in Indonesia, public spaces, and the intersection between modern and Indonesian vernacular architecture.

Nevine Rafa Kusuma is a lecturer at the Department of Architecture Universitas Indonesia. She received a bachelor's degree in architectural program Universitas Indonesia and a master's degree in interior design from University of Wesminster. Her research interest includes interior architecture, multisensory design, and exhibitions space.

Enira Arvanda is a lecturer at the Department of Architecture Universitas Indonesia. She received a bachelor's degree in architectural program Universitas Indonesia and a master's degree from Instituto Europeo di Design, Milan, Italy. She currently studies a doctoral program at the XYX Lab in Monash University. Her research interest includes interior architecture, urban interior and gender inclusive design.

Zafira Rahmatul Ummah is a student at Master Program Department of Architecture Universitas Indonesia. She received her bachelor's degree from the Department of Architecture Universitas Indonesia. Her research interests are in the relationship between architecture, human action, and the production of spatial experience. 


\section{References}

Andersen, L. L. (2007). Zoo education: from formal school programs to exhibit design and interpretation. International Zoo Yearbook, The Zoological Society of London, 38(1), 7581. https://doi.org/10.1111/j.1748-1090.2003.tb02066.x

Arnstein, S. R. (1969). A ladder of citizen participation. Journal of the American Planning Association, 35(4), 216-224. https://doi.org/10.1080/01944366908977225

Benneworth, P., Charles, D., \& Madanipour, A. (2010). Building localized interactions between universities and cities through university spatial development. European Planning Studies, 18(10), 1611-1629. https://doi.org/10.1080/09654313.2010.504345

Booher, D. E. (2008). Civic engagement and the quality of urban places. Planning Theory \& Practice, 9(3), 379-414.

Budge, K. (2018). Visitors in immersive museum spaces and Instagram: self, place-making, and play. The Journal of Public Space, 3(3), 121-138.

https://www.journalpublicspace.org/index.php/jps/article/view/534

Cartiere, C., \& Willis, S. (2008). Introduction. In C. Cartiere \& S. Willis (Eds.), The Practice of Public Art (pp. 1-6). Routledge.

Clayton, S., Fraser, J., \& Saunders, C. D. (2009). Zoo experiences: conversations, connections, and concern for animals. Zoo Biology, 28(5), 377-397. https://doi.org/10.1002/zoo.20186

Cleaver, F. (1999). Paradoxes of participation: questioning participatory approaches to development. Journal of International Development, 11(4), 597-612. https://doi.org/10.1002/(SICI)1099-1328(199906)11:4\%3C597::AID-

\section{JID610\%3E3.0.CO;2-Q}

Coe, J. C, (1985). Design and Perception: Making the Zoo Experience Real. Zoo Biology, 4(2), 197-208. https://doi.org/10.1002/Zoo.1430040211

Coe, J. C. (1997). Entertaining zoo visitors and zoo animals: an integrated approach. Proceedings of the American Zoo and Aquarium Association Annual Conference, 156162.

https://www.researchgate.net/publication/255595175_Entertaining_Zoo_Visitors_and_ Zoo_Animals_An_Integrated_Approach

Coley, R. (2019). Street smarts for smart streets. In P. Dibazar \& J. Naeff (Eds.), Visualizing the Street: New Practices of Documenting, Navigating and Imagining the City. Amsterdam University Press, 161-184. 
Cornell, E. H., Sorenson, A., \& Mio, T. (2003). Human Sense of Direction and Wayfinding. Annals of the Association of American Geographers, 93(2), 399-425. https://doi.org/10.1111/1467-8306.9302009

Correa de Jesus, S. (1994). Environmental Communication: Design Planning for Wayfinding. Design Issues, 10(3), 32-51. https://doi.org/10.2307/1511691

Department of Architecture, Faculty of Engineering, Universitas Indonesia. (2019). Furniture: Context, Response and Object Class Report. Department of Architecturem Faculty of Engineering, Universitas Indonesia.

Eaza. (2008). Education in zoos and aquaria. In: European Aquaria and Zoo Association Strategy.

Eyler, J. S. (2000). What do we most need to know about the impact of service-learning? Michigan Journal of Community Service Learning, Fall, 11-17. https://eric.ed.gov/?id=EJ620026

Frampton, K. (1991). Reflection on the autonomy of architecture: a critique of contemporary production. In D. Ghirardo [Ed] Out of site: A social Criticism of Architecture. Seattle, WA: Bay Press: 17-26.

Guijt, I. (2014). Participatory Approaches, Methodological Briefs: Impact Evaluation No. 5. Florence: UNICEF Office of Research.

Hasanin, A. A. (2013). Cultural diversity and reforming social behavior: a participatory design approach to design pedagogy, International Journal of Architectural Research: ArchNetIJAR, 7(2) 92-101.

https://www.proquest.com/docview/1429825823?pqorigsite $=$ gscholar $\&$ fromopenview $=$ true

Holgersen, S., \& Haarstad, H. (2009). Class, Community and Communicative Planning: Urban Redevelopment at King's Cross, London. Antipode, 41(2), 348-370. https://doi.org/10.1111/j.1467-8330.2009.00676.x

Hone, D. D. (2014, August 19). Why zoos are good. Retrieved from https://www.theguardian.com/science/lost-worlds/2014/aug/19/why-zoos-are-good.

Howarth, J., Currie, M. A., Morrell, E., Sorensen, J., \& Bengle, T. (2017). Challenges of building community-university partnerships in new poverty landscapes. Community Development, 48(1), 48-66. https://doi.org/10.1080/15575330.2016.1244696

Jabareen, Y. R. (2006). Sustainable Urban Forms: Their Typologies, Models, and Concepts. Journal of Planning Education and Research, 26(1) 38-52. 
Kensing, F. \& Greenbaum, J. (2012). Heritage: having a say. In J. Simonsen \& R. T. Routledge [Eds] International Handbook of Participatory Design, London: Routledge, 21-36.

Ludlum, S. (2003). Historic Zoo Architecture: Creating New Meaning, MS Thesis, North Carolina State University-Raleigh.

Lynch, K. (1960). The image of the city. Cambridge, MA: MIT Press.

Moomaw, S. M. (2016). Improving local results: fusing community design and community development. Community Development, 47(5), 670-682. https://doi.org/10.1080/15575330.2016.1228688

Pedersen, J. (2016). War and peace in codesign. Codesign, 23(3), 171-184. https://doi.org/10.1080/15710882.2015.1112813

Robertson, R. \& Simonsen, J. (2012). Challenges and Opportunities in Contemporary Participatory Design. Design Issues, 28(3), 3-9. https://doi.org/10.1162/DESI_a_00157

Rodriguez, C. M. (2017). A method for experiential learning and significant learning in architectural education via live projects. Arts and Humanities in Higher Education, 17(3), 279-304. https://doi.org/10.1177\%2F1474022217711878

Roe, K., McConney, A., \& Mansfield, C. F. (2014). The Role of Zoos in Modern Society-A Comparison of Zoos' Reported Priorities and What Visitors Believe They Should Be. Anthrozoös: A multidisciplinary journal of the interactions of people and animals, 27(4), 529-541. https://doi.org/10.2752/089279314X14072268687808

Salama, A. (2009). Transformative Pedagogy in Architecture \& Urbanism. Solingen: UmbauVerlag.

Sanoff, H. (2000). Community Participation Methods in Design and Planning. New York, NY: John Wiley \& Sons Inc.

Sanoff, H. (2008). Multiple views of participatory design. International Journal of Architectural Research, 23(1), 131-43. https://www.academia.edu/download/34536642/Multiple_Views_of_Participatory_Des ign.pdf

Sanders, E. B.-N. \& Stappers, P. J. (2008). Co-creation and the new landscapes of design. Codesign, 4(1), 5-18. https://doi.org/10.1080/15710880701875068

Uffelen, C. V. (2010). Street Furniture. Berlin: Braun Publishing.

Whyte Jr., W. (1980). The Social Life of Small Urban Spaces. Conservation Foundation.

Yücel, G. F. (2013). Street furniture and amenities: Designing the user-oriented urban landscape. In Advances in landscape architecture. IntechOpen. 